\title{
Eksplorasi Limbah Kaca Pada Badan Keramik Stoneware
}

\author{
Rabbani Winsa Rizqi ${ }^{1}$, Dedi Ismail ${ }^{2}$ \\ 1 Program Studi Desain Produk, Fakultas Arsitektur dan Desain, Institut Teknologi Nasional, Bandung \\ 2 Program Studi Desain Produk, Fakultas Arsitektur dan Desain, Institut Teknologi Nasional, Bandung \\ Email: winsaaa@mhs.itenas.ac.id ${ }^{1}$, ismail@itenas.ac.id ${ }^{2}$
}

\begin{abstract}
Abstrak
Objektif dari studi eksplorasi limbah kaca pada tanah liat untuk produk keramik ini adalah untuk mencari adanya kebaruan dan inovasi visual untuk produk keramik yang sekarang sudah terancam karena adanya keramik produksi massal dengan karakteristik "handmade". Eksistensi produksi massal pada produk keramik "handmade" akan berdampak pada nilai dan harga produk keramik yang memang benar-benar dibuat dengan tangan, teknik yang lebih rumit, serta craftsmanship tinggi. Berangkat dari studi industri Kyomi, penulis menggunakan metode design-by-doing dan eksplorasi untuk mengembangkan produk keramik dari bahan baku yang tersedia dan terjangkau oleh industri. Melalui pencarian kemungkinan akan identitas baru melalui eksplorasi pencampuran tanah liat stoneware dengan limbah kaca, diharapkan akan memunculkan potensi estetis yang baru sehingga dapat mengangkat integritas dan nilai pada produk keramik handmade yang tidak mudah ditiru dan diproduksi secara massal.
\end{abstract}

Kata kunci: Keramik, Eksplorasi, Kerajinan, Limbah Kaca.

\begin{abstract}
The objective of glass waste exploration in clay for ceramic products has a mean to look for novelties and innovations for ceramic products which are now under threat due to mass production ceramics with "handmade" characteristics. The existence of "handmade" mass produced ceramic products will have an impact on the value and price of ceramic products that are actually crafted by hand with more complex techniques, and high craftsmanship. From Kyomi Ceramic Studio's case studies, the author uses design-by-doing methods and experimental research to develop ceramic products from available and affordable raw materials for the industry. By looking for the possibility of a new identity through the exploration of mixing stoneware clay with glass waste, it is hoped that it will generate new aesthetic potential and can raise the integrity and value of handmade ceramic products that are not easily imitated or mass produced.
\end{abstract}

Keywords: ceramic, exploration, craft product, glass waste

\section{Pendahuluan}

Istilah keramik atau gerabah sudah tidak terdengar asing di kalangan masyarakat Indonesia. Keramik yang dipercaya ditemukan secara tidak sengaja sejak 15,000-10,000 tahun sebelum Masehi memiliki peranan penting dalam perkembangan kebudayaan manusia [1]. Di Indonesia sendiri kehadiran keramik tradisional yang sudah sejak dulu berjalan dapat ditemukan di industri seperti Kasongan di Yogyakarta dan Plered di Purwakarta yang sudah sejak lama melakukan kegiatan mengolah keramik dengan sistem hirarki pengrajin. Produk keramik akhirnya berkembang sesuai dengan perkembangan dan permintaan pasar. Akhir-akhir ini, selain keramik tradisional yang bergantung pada pengrajin setempat, banyak studio keramik mandiri seperti Kandura di Jakarta yang berjalan sebagai studio mandiri. Berbekal dengan adanya ahli kriya keramik dan desainer, studio keramik mandiri biasanya menghasilkan produk keramik dengan fungsi yang lebih kontemporer untuk memenuhi pasar yang dipilih melalui proses eksplorasi [2]. Dengan menjual visual "imperfection" atau ketidaksempurnaan sebagai identitas pada produk handmade, studio mandiri membuka pasar baru bagi penikmat produkproduk artisan yang terkesan eksklusif dan mahal. 
Walaupun memiliki pasar eksklusif, persaingan muncul ketika Cina sebagai pengimpor keramik terbesar, yang memiliki kemajuan teknologi, ketersediaan bahan, e-commerce serta logistik murah dari Cina, dapat memproduksi produk dengan rupa handmade dengan harga yang jauh lebih murah. Elisa Siregar sebagai Ketua Umum Asosiasi Keramik Indonesia (AKI) mengatakan bahwa keramik import yang terus bertambah dapat mengancam keberlangsungan keramik industri dan studio saat ini. Jumlah keramik impor diperkirakan naik sebesar 22\% setiap tahunnya. Bahkan di tahun 2018, angka tersebut naik hingga 55\%, sedangkan keramik dalam negeri hanya dapat mengekspor $18 \%$ [3].

Selain itu Industri Studio Mandiri yang berfokus pada produk eksklusif buatan tangan terancam dengan adanya produk cina dengan visual yang mirip atau serupa. Selain Cina memiliki keuntungan dengan cara memproduksi produk mereka dengan masal--sehingga produk yang mereka tawarkan dijual dengan harga yang jauh lebih murah--mereka memiliki bahan-bahan yang lebih unggul daripada Industri yang berada di Indonesia, sedangkan Industri di Indonesia memiliki keterbatasan dalam hal memperoleh bahan baku dengan harga terjangkau.

Maka dari itu harus dilakukan pemanfaatan dari bahan baku yang tersedia dengan cara mengeksplorasi bahan baku tersebut untuk mencari kebaruan rupa atau potensi estetika.

\section{Metodologi}

Penelitian ini merupakan penelitian eksperimen dengan metode yang Design-by-Doing dengan eksperimentasi pencampuran limbah kaca pada material tanah liat stoneware untuk mengetahui apakah adanya visual baru yang dapat ditimbulkan. Menurut Andry, pada jurnal penelitian "Penerapan Metode Design By Doing Melalui Eksplorasi Bahan Non Konvensional Untuk Membangun Industri Kerajinan Kreatif Khas Indonesia", pendekatan metoda Design-by-Doing--yang telah dilakukannya selama 6 tahun dan diterapkan pada produk dari bahan non konvensional--dapat menghasilkan karyakarya kerajinan inovatif bernilai tinggi [3]

Metode Design-by-doing dilakukan dengan melihat respon dari perlakuan yang diberikan pada sebuah material untuk kemudian dianalisis dan dipilah. Langkah-langkah dari metode tersebut dapat disimpulkan menjadi 4 langkah seperti gambaran di bawah ini.

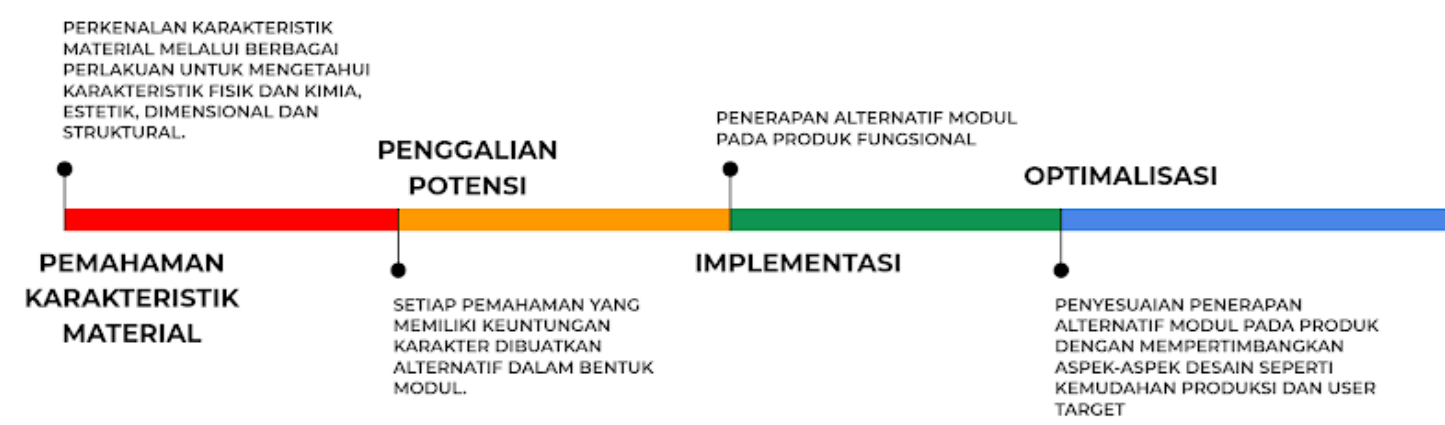

Gambar 1. elaborasi penulis dari Jurnal Penerapan Metoda Design by Doing Melalui Eksplorasi Bahan Non Konvensional Untuk Membangun Industri Kerajinan Kreatif khas Indonesia 


\subsection{Pemahaman Karakteristik Material}

Penulis mengumpulkan data awal untuk preparasi eksplorasi berupa studi Literatur dan Analisis Karakteristik Material Limbah kaca dan Tanah Liat Stoneware. Kemudian data tersebut akan menjadi acuan dan batasan pada eksplorasi pencampuran kedua material tersebut.

\subsubsection{Stoneware}

Stoneware merupakan istilah umum untuk lempung yang memiliki titik leburnya atau matang mencapai $1100^{\circ} \mathrm{C}-1200^{\circ} \mathrm{C}$. Selain suhu tinggi pembakarannya, lempung stoneware yang sudah dicampur dengan mineral lainnya memiliki pori-pori yang rapat daripada lempung earthenware dan tingkat kekuatan seperti batu; maka itu dinamakan stoneware, stone yang berarti batu. Stoneware biasa ditemukan pada industri dan studio mandiri karena bahannya yang tergolong murah dan kuat. Stoneware sendiri sangat versatile dari segi harga, pemanfaatan, dan pengolahan. Biasanya setiap industri atau penyuplai tanah memiliki presentase resep stoneware yang berbeda-beda [2].

Industri Kyomi memakai 3 jenis stoneware berbeda. Setelah menganalisis semua jenis stoneware yang dipakai, penulis memilih stoneware A Yudi sebagai material utama dalam eksplorasi ini.

\subsubsection{Limbah Kaca}

Limbah kaca yang akan digunakan pada penelitian ini adalah limbah kaca botol minuman dengan warna biru, coklat dan hijau. Limbah Kaca botol minuman memiliki titik leleh yang hampir sama dengan keramik, yaitu pada suhu $1000^{\circ} \mathrm{C}-1100^{\circ} \mathrm{C}$

Data mengenai pencampuran limbah kaca dan bodi stoneware akan diperoleh dengan cara memberikan perlakukan-perlakuan khusus seperti eksperimentasi dengan teknik pencampuran, teknik pembentukan, teknik dan suhu pembakaran, dan finishing untuk menggali potensi estetis dari eksplorasi tersebut. Kontrol eksperimen yang akan disiapkan berupa lempengan 5x5 keramik stoneware dengan suhu bakar 800 dan 1200 dengan finishing glasir transparan glossy, glasir transparan matte, dan tanpa glasir.

\subsection{Penggalian Potensi}

Dari hasil eksperimen pertama akan dikembangkan untuk melihat adanya potensi dimensi dan struktur pada eksperimen pencampuran tanah liat stoneware dan limbah kaca. Hal tersebut dapat dilakukan dengan memperbesar atau memperkecil ukuran, mengeksplorasi bentuk melalui kemungkinan teknik produksi seperti cetak, putar, slabbing. Hasil akhir dari penggalian potensi akan berupa data analisis dari potensi dimensi dan potensi struktur

\subsection{Implementasi}

Potensi estetis, dimensi, dan struktur dari langkah metode di atas kemudian akan dikemas menjadi satu dan diimplementasikan pada beberapa alternatif produk fungsional. Analisis dan Evaluasi dari tahap implementasi akan mengantarkan modul untuk diaplikasikan pada satu produk fungsional dengan ketiga potensi terbaik. 


\section{$2.4 \quad$ Optimalisasi}

Tahap optimalisasi akan melibatkan konfigurasi dan aspek desain pada produk yang memiliki kualitas baik dari tiga kriteria potensi.

\section{Diskusi}

Penggunaan kaca pada keramik bukanlah yang pertama kali dilakukan. Di Indonesia sendiri, pemanfaatan limbah kaca digunakan pada glasir keramik telah diteliti oleh Arif Suharson pada bodi keramik stoneware. (Suharson, 2017, 64). Selain dari itu, hasil wawancara dengan salah satu pengrajin dan asisten Studio Asmudjo, Tihar, menerangkan pemanfaatan kaca bubuk sebagai penguat dari bodi keramik sendiri sudah lama digunakan oleh beberapa industri tile sebagai pendukung proses sintering dan penguat keramik.

\subsection{Proses Eksplorasi}

Proses eksplorasi dilakukan dengan limbah kaca yang sudah dipecahkan. Kemudian pecahan kaca tersebut dibagi menjadi 4 bagian sesuai dengan ukurannya, disaring melalui 3 jenis saringan yang memiliki kerapatan berbeda. (saringan teh, saringan minyak, dan saringan mie). Kaca kemudian ditaruh pada 4 wadah dan dilabeli sebagai berikut. Kaca Halus 1, Kaca Halus 2, Kaca Halus Medium, dan Kaca Halus Kasar (dengan ukuran maksimal $2 \mathrm{~cm}$ ).

\subsubsection{Perlakuan dan hasil Eksplorasi 1}

Perlakuan pertama adalah pencampuran pecahan kaca halus 1, kaca halus 2, kaca medium, dan kaca kasar langsung dengan bodi keramik dengan konsistensi 15\%, 30\% dan 50\% dicampurkan pada 100 gram Tanah Stoneware Sukabumi. Setelah dicampurkan, bodi keramik dituang pada gipsum agar cepat kering, lalu dipotong sesuai ukuran tes $5 \times 5 \mathrm{~cm}$. Modul kemudian akan dibakar pada suhu $800^{\circ} \mathrm{C}$ dan $1200^{\circ} \mathrm{C}$ dengan finishing gelasir matte, gelasir glossy, dan tanpa gelasir.

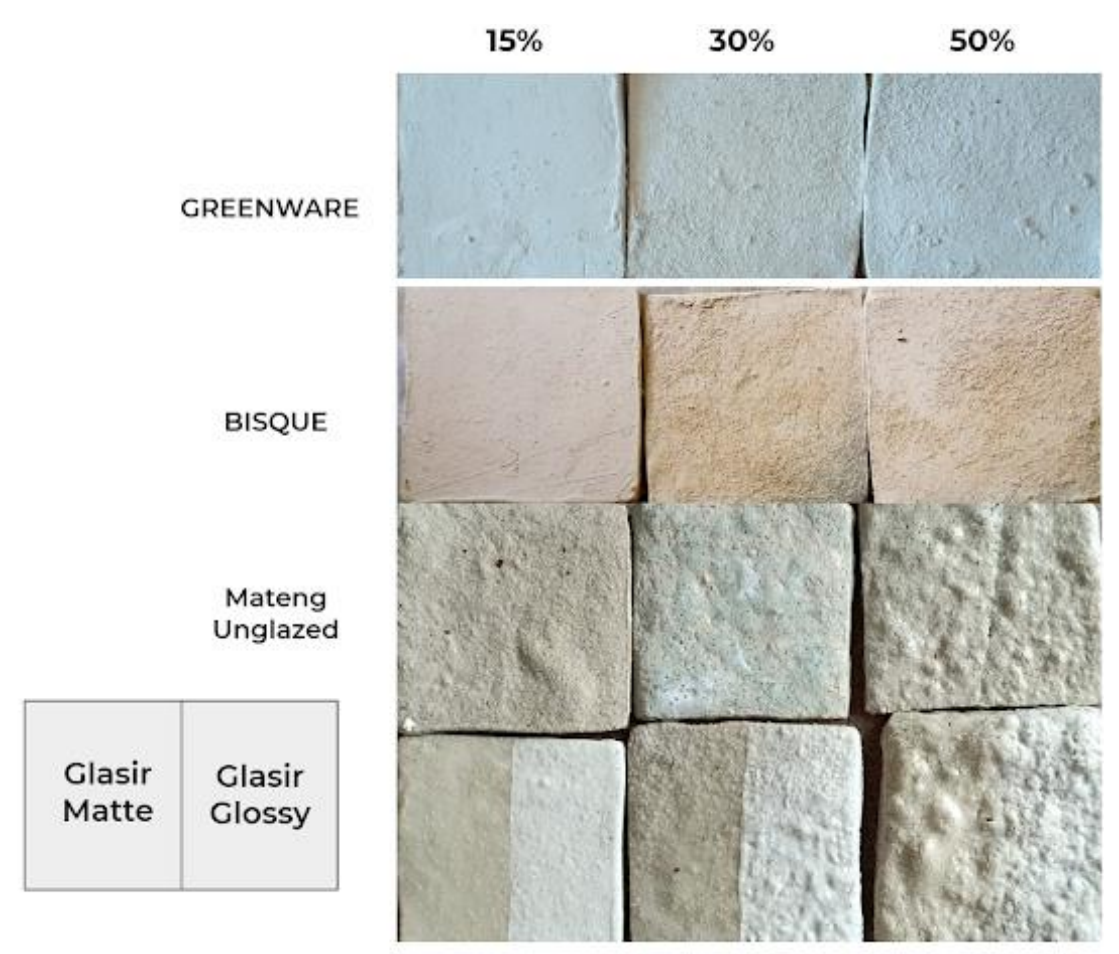

Gambar 2 . Eksplorasi Kaca Halus 1. 
Indonesia

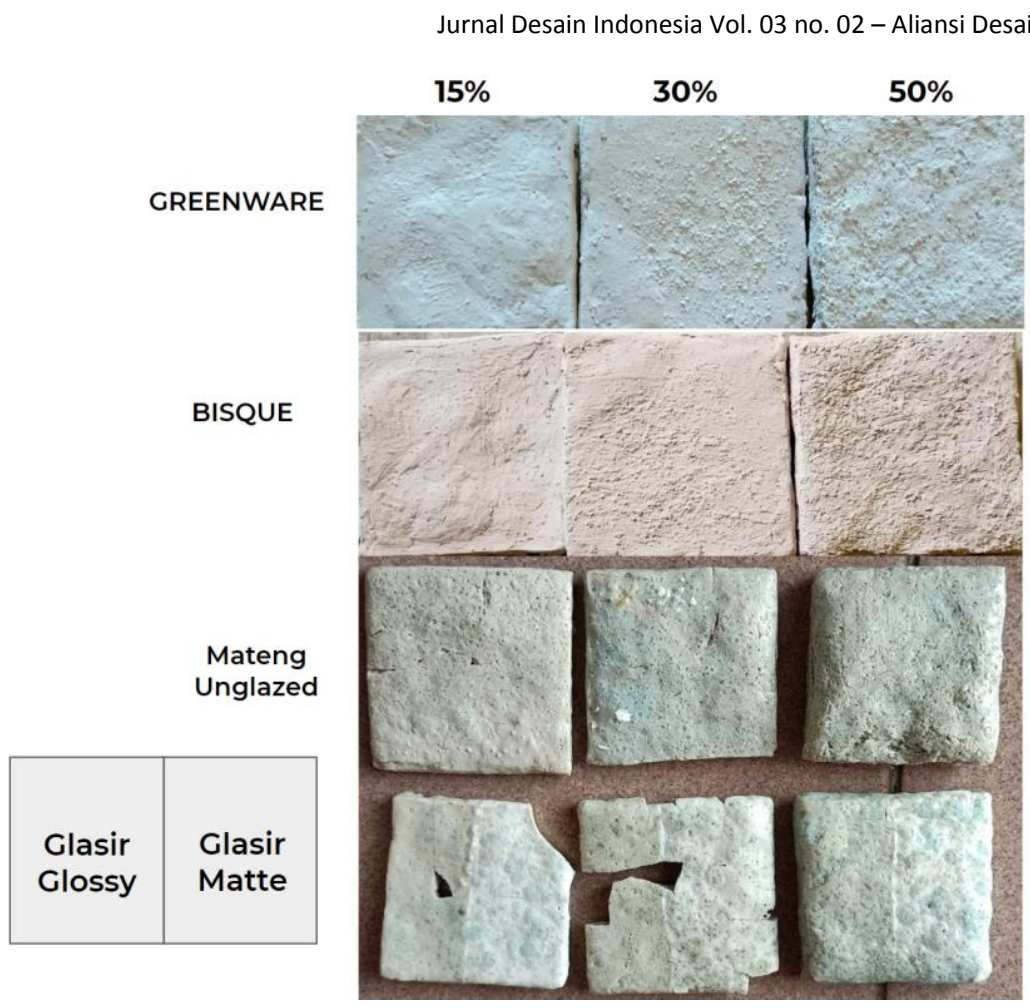

Page | 5

Gambar 3. Eksplorasi Kaca Halus 2

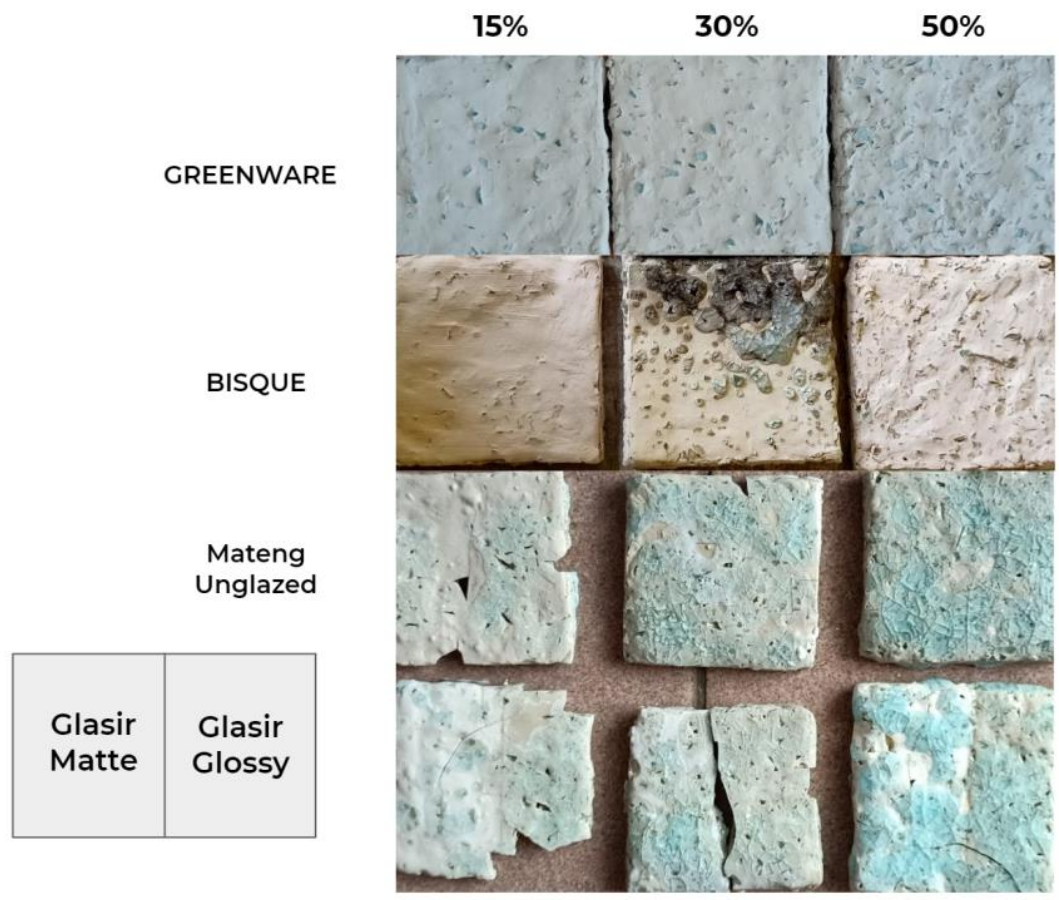

Gambar 4. Eksplorasi Kaca Medium. 


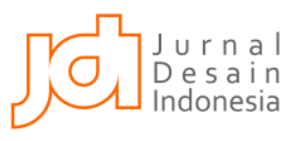

Jurnal Desain Indonesia Vol. 03 no. 02 - Aliansi Desainer Produk Industri

$15 \%$

Gambar 5. Eksplorasi Kaca Kasar.

BISQUE

Mateng

Unglazed

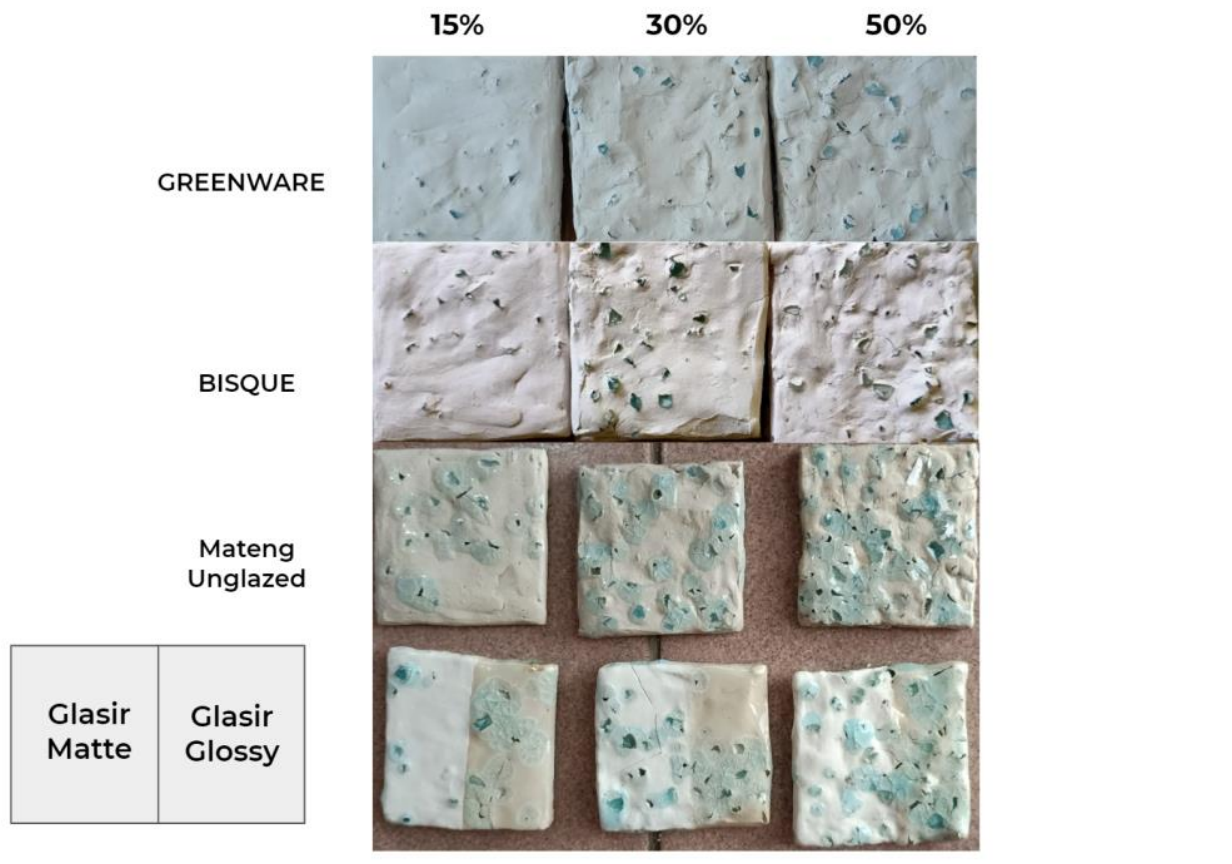

\begin{tabular}{|l|l|}
\hline Glasir & Glasir \\
Matte & Glossy \\
\hline
\end{tabular}
Indonesia GREENWARE

Unglazed

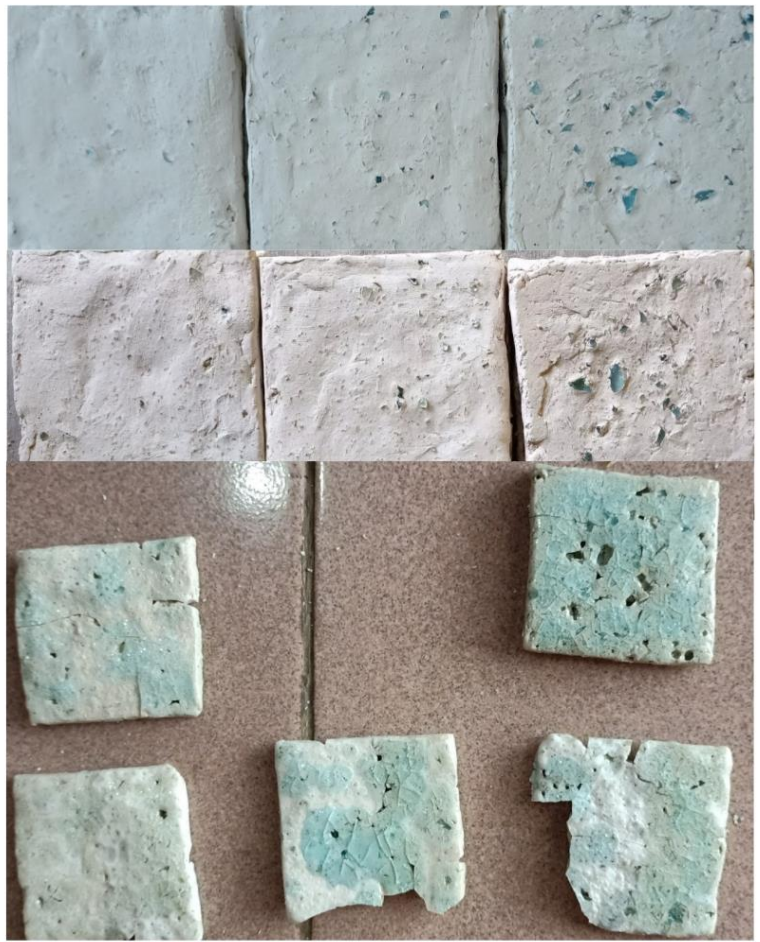

Gambar 6. Eksplorasi Kaca Mix.

\subsubsection{Perlakuan dan Hasil Eksplorasi 2}

Perlakuan eksplorasi ke 2 adalah penempelan kaca langsung pada modul tanah dengan teknik slabbing. Tanah yang telah dibuatkan lembaran kemudian dipotong dengan ukuran $10 \mathrm{~cm} \times 5 \mathrm{~cm}$. Kemudian kaca akan langsung ditempelkan pada bodi modul dan digiling menggunakan rolling pin. Setelahnya, modul akan dilengkungkan. 

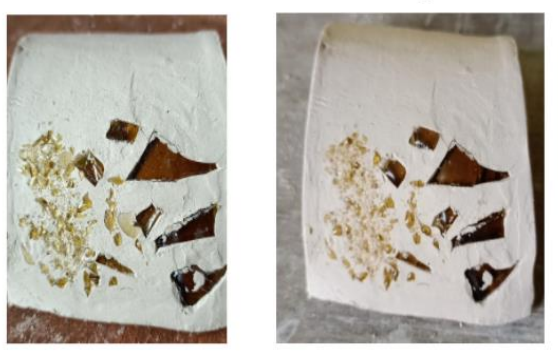

MATANG
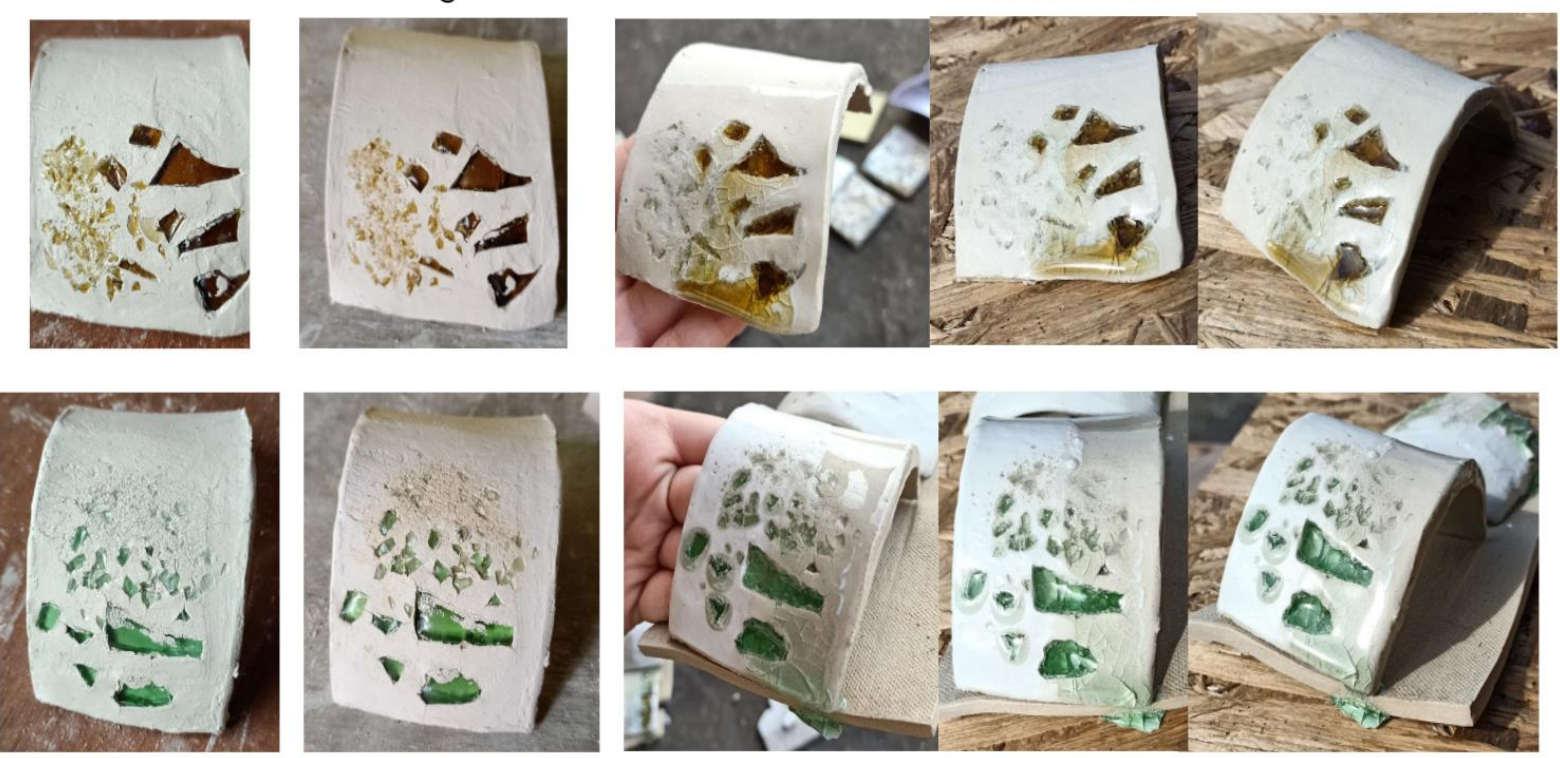

age | 7

Gambar 7. Perlakuan Eksplorasi 2.

\subsubsection{Perlakuan dan Hasil Eksplorasi 3}

Perlakuan eksplorasi ke 3 adalah penempelan kaca menggunakan slip (lumpur) pada modul tanah dengan teknik slabbing. Tanah yang telah dibuatkan lembaran kemudian dipotong dengan ukuran 10 $\mathrm{cm} \times 5 \mathrm{~cm}$, kemudian dilengkungkan. Setelah tanah dilengkungkan, slip dibubuhin pada bagian yang akan ditempelkan pecahan kaca. Setelah didiamkan selama 1 jam, pecahan kaca akan ditekan sedikit kedalam menggunakan kain untuk melindungi jari dari pecahan kaca yang tajam.

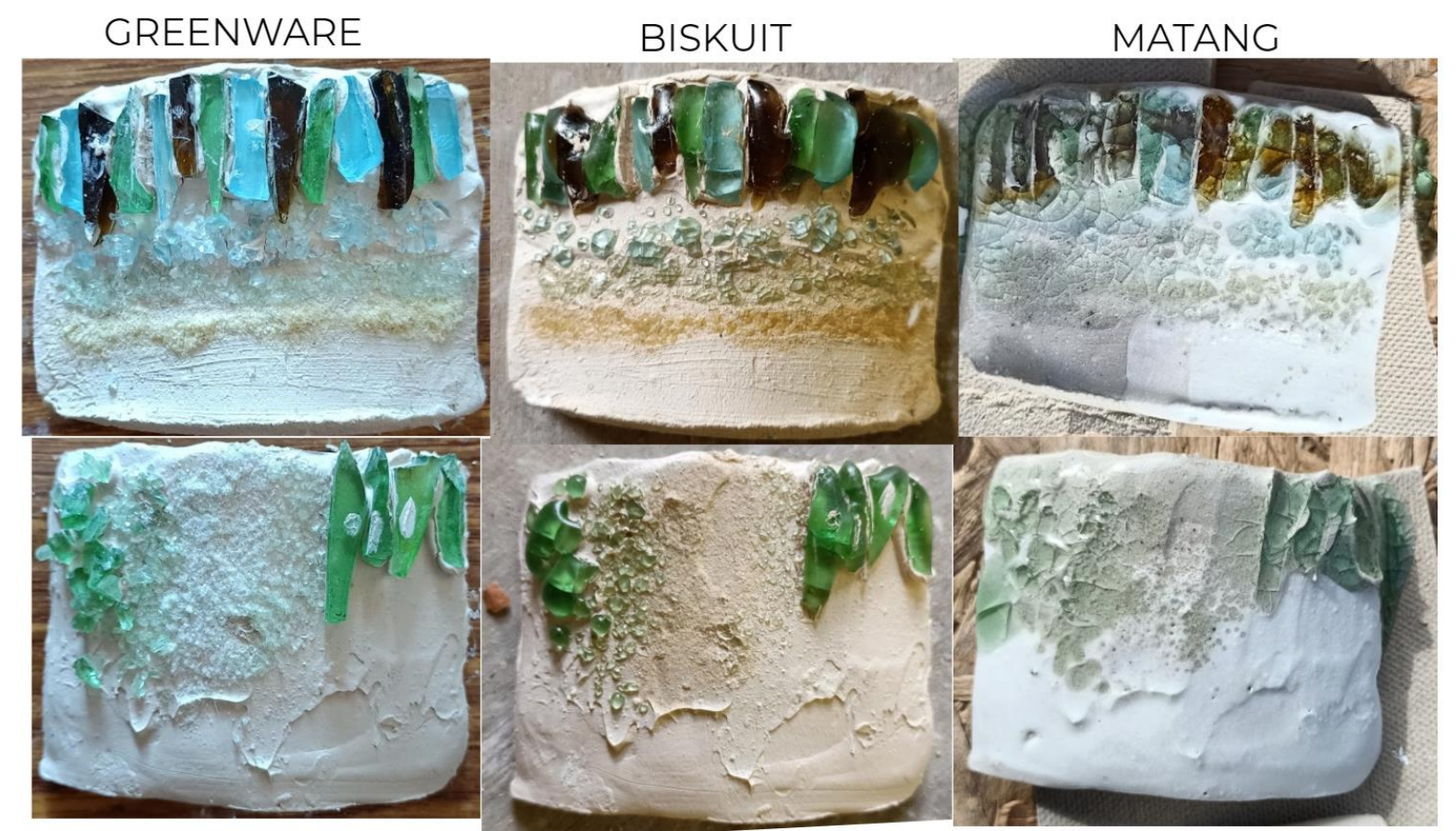

Gambar 8 . Perlakuan Eksplorasi 3. 


\subsection{Analisis Eksplorasi}

\subsubsection{Analisis Eksplorasi 1}

Pencampuran limbah kaca yang langsung dicampurkan pada bodi keramik menghasilkan warna (bercak) yang tidak beraturan. Sebagian dari tes bakar matang menjadi masalah karena titik leleh kaca pada (1000 C)lebih rendah daripada keramik dan glasir (1250 C). Sehingga sebagian besar dari hasil tes bakar pun menempel pada plat tungku dan harus dipatahkan dari plat agar dapat diambil dari tungku.

Warna dari kaca sendiri lebih terlihat jelas pada glasir matte, namun pada glasir glossy pecahan kaca yang tajam lebih tertutupi. Jika eksplorasi ini dilanjutkan maka, yang menjadi pertimbangan adalah teknis pengkaryaan-nya berupa penempatan campuran tanah pada lapisan atas atau dalam (agar lelehan kaca tidak jatuh pada plat tungku. Atau penggunaan kaca yang lebih tahan panas seperti kaca patri. Atau pembakaran titik rendah sesuai dengan titik leleh kaca.

\subsubsection{Analisis Eksplorasi 2}

Eksplorasi Teknik penempelan pada permukaan bodi keramik dapat dilihat pada hasil eksplorasi menimbulkan potensi baik karena dapat terkontrol dengan lebih mudah. Hasil dari eksplorasi ini, sama halnya dengan eksplorasi pencampuran langsung, harus ditempatkan pada bagian suatu karya atau di sebuah bidang datar atau cekung (ubin, mangkuk), untuk memudahkan produksi dan menghindari lelehan kaca yang berpotensi dapat menempel pada plat tungku bakaran. Namun pada eksplorasi perlakuan ke 2, ditemukan pada tahap greenware, terdapat retakan yang cukup besar. Hal tersebut dapat berpotensi yang berbahaya pada sebuah karya dengan dimensi yang cukup besar.

\subsubsection{Analisis Eksplorasi 3}

Eksplorasi Teknik penempelan pada permukaan bodi keramik dapat dilihat pada hasil eksplorasi menimbulkan potensi yang unik. Terutama dengan kombinasi warna lebih dari 1 yang dapat diatur atau dikontrol dengan lebih mudah. Hasil dari eksplorasi ini, sama halnya dengan eksplorasi pencampuran langsung, harus ditempatkan pada bagian suatu karya atau di sebuah bidang datar atau cekung (ubin, mangkuk), untuk memudahkan produksi dan menghindari lelehan kaca yang berpotensi dapat menempel pada plat tungku bakaran. Ditemukan bahwa hasil dari kaca yang ditempel dengan slip dapat mengurangi retakan pada permukaannya jika dibandingkan dengan penempelan langsung pada permukaan bodi keramik.

\section{Kesimpulan.}

Dari Hasil Eksplorasi diatas, penulis mememilih untuk mengimplementasi eksplorasi ke 3 pada produk fungsional dengan pertimbangan :

1. Efek visual yang optimal ditimbulkan berbanding dengan usaha atau teknik produksi.

2. Teknik dan Usaha Produksi yang lebih mudah dan ringkas serta dapat direplikasi dengan beberapa teknik pengkaryaan keramik.

3. Hasil dan pengkaryaan eksplorasi dapat lebih mudah dikontrol sesuai dengan harapan.

4. Minimal resiko retak dan gagal pada karya dengan dimensi yang besar maupun kecil.

5. Eksplorasi lebih mudah direplikasi. 
Potensi implementasi pada produk mengacu pada analisis bahwa perlakuan eksplorasi tersebut dapat diimplementasi pada produk non-food grade dikarenakan penggunaan material kaca yang perlu diteliti lebih lanjut keamanannya. Hasil Eksplorasi dapat diimplementasikan pada produk home decor item berupa tempat dupa, vas bunga basah atau kering, piring hias, dan pot tanaman.

\section{Referensi}

[1] A. R. Suparta, Pengetahuan Bahan Dasar Keramik, Bandung: Institut Teknologi Bandung, 2012.

[2] A. A. Satrio, "Kriya Keramik : Wujud, Posisi, dan Perannya di Masa Kini," Corak, Jurnal Seni Kriya, vol. 1, no. 2, pp. 167-176, 2013.

[3] M. Agustinus, "Impor Keramik Naik 51\% di Awal 2018, Industri Domestik Terancam," Kumparan, 2018.

[4] Andry, "Penerapan Metoda Design By Doing Melalui Eksplorasi Bahan Non Konvensional Untuk Membangun Industri Kerajinan Kreatif Khas Indonesia," Jurnal Lib ITENAS, pp. 1-13, 2010.

[5] A. Suharson, "Eksplorasi Limbah Kaca Pada Finishing Gelasir Bodi Keramik," Corak, Jurnal Kriya Indonesia, vol. 6, no. 1, p. 55, Mei - Oktober 2017. 